\title{
Concepts of functioning and health important to people with systemic sclerosis: a qualitative study in four European countries
}

\author{
Tanja A Stamm, ${ }^{1,2}$ Malin Mattsson, ${ }^{3,4}$ Carina Mihai, ${ }^{5}$ Juliane Stöcker, ${ }^{6}$ Alexa Binder, ${ }^{1}$ \\ Bettina Bauernfeind, ${ }^{1}$ Georg Stummvoll, ${ }^{1}$ Gunvor Gard ${ }_{1}^{4}$ Roger Hesselstrand, ${ }^{7}$ \\ Gunnel Sandqvist, ${ }^{7}$ Oana Draghicescu, ${ }^{5}$ Ana Maria Gherghe, ${ }^{5}$ Malina Voicu, ${ }^{8}$ \\ Klaus P Machold, ${ }^{1}$ Oliver Distler, ${ }^{6}$ Josef $S$ Smolen, ${ }^{1}$ Carina Boström ${ }^{9}$
}

\begin{abstract}
${ }^{1}$ Department of Internal Medicine III, Division of Rheumatology, Medical University of Vienna, Vienna, Austria

2Department of Health, Division of Occupational Therapy, FH Campus Wien, University of Applied Sciences, Vienna, Austria ${ }^{3}$ Department of Physiotherapy, Sunderby Hospital, Luleå, Sweden

${ }^{4}$ Department of Health Sciences, Luleå University of Technology, Luleå, Sweden 5 Internal Medicine and Rheumatology Department, Carol Davila University of Medicine and Pharmacy, Cantacuzino Hospital, Bucharest, Romania

${ }^{6}$ Department of Rheumatology and Institute for Physical Medicine, University Hospital Zurich, Zurich, Switzerland ${ }^{7}$ Department of Rheumatology, Lund University, Lund, Sweden ${ }^{8}$ The Research Institute for Quality of Life, Romanian Academy of Science, Bucharest, Romania ${ }^{9}$ Department of Neurobiology, Care Sciences and Society, Division of Physiotherapy, Karolinska Institutet, Stockholm, Sweden
\end{abstract}

\section{Correspondence to} Tanja Stamm, Department of Internal Medicine III, Division of Rheumatology, Medical University of Vienna, Waehringer Guertel 18-20, 1090 Vienna, Austria;

tanja.stamm@meduniwien. ac.at

Accepted 1 April 2011

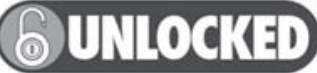

This paper is freely available online under the BMJ Journals unlocked scheme, see http:// ard.bmj.com/info/unlocked.dtl

\begin{abstract}
Objective To describe the experiences of people with systemic sclerosis (SSc) in different European countries of functioning and health and to link these experiences to the WHO International Classification of Functioning, Disability and Health (ICF) to develop a common understanding from a bio-psycho-social perspective. Method A qualitative multicentre study with focusgroup interviews was performed in four European countries: Austria, Romania, Sweden and Switzerland. The qualitative data analysis followed a modified form of 'meaning condensation' and the concepts that emerged in the analysis were linked to the ICF.
\end{abstract}

Results 63 people with SSc participated in 13 focus groups. In total, 86 concepts were identified. 32 (37\%) of these were linked to the ICF component body functions and structures, $21(24 \%)$ to activities and participation, $26(30 \%)$ to environmental factors, $6(7 \%)$ to personal factors and $1(1 \%)$ to the health condition itself. 19 concepts (22\%) were identified in all four countries and included impaired hand function, household activities, paid work, drugs, climate and coldness, support from others and experiences with healthcare institutions, nonpharmacological treatment, social security and benefits.

Conclusion Concepts identified in all four countries could be used for guiding clinical assessment, as well as interdisciplinary team care and rheumatological rehabilitation for patients with SSc. For a full understanding of the aspects of the disease that were most relevant to people with SSc, people with SSc from multiple countries needed to be involved.

\section{INTRODUCTION}

Systemic sclerosis (scleroderma; SSc) is a systemic, inflammatory and autoimmune disorder characterised by the excessive deposition of extracellular matrix in the skin and in inner organs which can lead to a wide range of organ damage. ${ }^{1}$ Based on the amount of skin affected, a limited and a diffuse form of SSc are distinguished. Skin thickening occurs earlier in diffuse disease and severe skin involvement is a predictor of later organ involvement and outcome. ${ }^{23}$ Skin induration as well as joint and muscle involvement often lead to a progressive reduction in the range of motion. Up to $90 \%$ of patients with SSc report loss of hand grasp ability related to factors such as skin sclerosis of fingers, ischaemia with ulcers, arthralgia, calcifications and wrist extension reduction leading to severe hand disability.
These may be significant factors for difficulties in performing activities of daily living. ${ }^{4-9}$ SSc affects both physical and mental health-related quality of life, ${ }^{10}$ which may cause problems of functioning and restriction in participation in society. It may thus be essential for optimal patient care to understand functioning from a bio-psycho-social perspective, which is currently best represented in the framework and model of the WHO International Classification of Functioning, Disability and Health (ICF). ${ }^{11}$

The ICF comprises several categories ranging from body functions and structures, activities and participation to contextual factors. According to these categories, problems of patients with a certain disease can be classified. If a patient reports problems with fine motor hand function, this may be linked to the corresponding ICF category (d440fine hand use) and can thus be 'translated into ICF language'. Based on this 'translation', problems of patients with a certain disease can be described in a frame of reference and compared with those of other patients, of other countries, of other diseases and so on. ICF categories are worded in neutral language, so that a certain category can either be a 'problem' or a 'resource'. ${ }^{11}$ In SSc, no data were available on functioning in daily life of people from different European countries from such a comprehensive, bio-psycho-social perspective. Qualitative methodology provides the possibility of exploring the perspective of those who experience a disease. ${ }^{12} 13$ In SSc, only a few previous studies have used a qualitative research approach. ${ }^{14-16}$

The aim of this study was to describe the experiences of people with SSc in different European countries of functioning and health and to link these experiences to the WHO ICF to develop a common understanding from a bio-psycho-social perspective.

\section{METHODS \\ Design}

A qualitative focus-group interview study ${ }^{17}{ }^{18}$ was performed in the following four European countries: Austria (A), Romania (R), Sweden (S) and Switzerland $(\mathrm{CH})$.

\section{Participants}

People with SSc were recruited from the outpatient departments of the participating centres. 
Patients who were eligible had to meet the American College of Rheumatology criteria for SSc, ${ }^{19}$ were asked whether they would like to participate in the study and were fully informed about the study procedures. Patients who were willing to participate gave written informed consent according to the Declaration of Helsinki. The study was approved by the institutional review boards and ethics committees of the participating centres. Sampling of patients in each country followed a maximum variation strategy ${ }^{20}$ based on the following criteria: age, sex, disease duration and diffuse/limited SSc.

\section{Sample size}

Two to four focus groups were conducted in each country. From earlier studies, ${ }^{21-23}$ we estimated that about $8-10$ focus groups were needed to obtain data of sufficient depth and breadth. Qualitative research typically uses small sample sizes with a diverse range of participants. In this perspective, individual experiences which can express variations of a given phenomenon and potentially raise new and unexpected issues are more important than numbers and frequencies. ${ }^{23}$

\section{Data collection}

All focus groups were chaired by a trained and experienced moderator together with one assistant responsible for observing the group and recording the data. The five questions for the focus groups were based on the following ICF domains: body functions (eg, "If you think about your body and mind, what does not work the way it is supposed to?") and structures, activities and participation, environmental and personal factors. Negative and positive aspects were dealt with by, for example, referring to barriers, facilitators and resources. According to a predefined protocol in an earlier study, ${ }^{23}$ the questions were translated, back translated and the translations analysed so that a final version could be established for the participating countries. Each group involved up to seven people. A short introduction including the purpose of the study was given in lay terms to all patients at the beginning of each focus group. The focus-group interviews were tape-recorded and transcribed verbatim.

\section{Data analysis}

Qualitative data analysis followed a modified form of 'meaning condensation', ${ }^{24}$ which involved the following steps: first, the transcribed interviews were read through by the principal investigators in each country $(\mathrm{AB}, \mathrm{CM}, \mathrm{MM} / \mathrm{CB}, \mathrm{JS})$ to obtain an overview of the collected data. Second, the data were divided into 'meaning units', which were defined as specific units of text, either a few words or a few sentences with a common meaning. ${ }^{25}$ Third, the concepts contained in the meaning units were identified. A meaning unit could contain more than one concept. Not all concepts had to be on the same level (could be either lower-level or higher-level concepts) with the same range of meanings and attributes. So lower-level concepts could be grouped together under a higher-level concept, which had then to cover the whole content and attributes of the lower-level concepts. An example is described in figure 1.

When these analyses had been made in each country, the concepts were translated into English. Then, the concepts from all countries were combined (TS) using the framework of the ICF-for example, concepts from all countries relating to the ICF domain body functions were grouped under this domain and compared with each other for similarities and differences. Lower-level concepts (no matter which country) were grouped
Example of a meaning unit :

"And I take pills for my depression and now I'm calmer, I find the comfort, this is it, I can't help it. I wasn't sleeping, I was losing weight and I didn't know what it was. So I went to a psychiatrist. He gave me anti-depression pills, I wasn't sleeping at all."

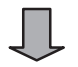

Example of a lower-level concept extracted from this meaning unit: 'Depressive mood'

Example of a higher -

level concept to which

'Depressive mood' relates :

'Emotional issues'
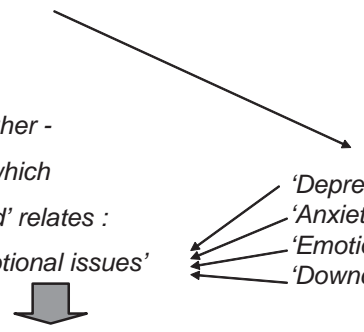

Linking to the ICF: b152 emotional functions - ' $b$ ' is referring to body functions and structures

Figure 1 An example of the qualitative analysis: a meaning unit, a lower-level concept extracted from this meaning unit and the corresponding higher-level concept and ICT category.

under higher-level concepts (from the same or any other country). An example was the higher-level concept 'emotional issues', which finally included the following lower-level concepts: anxiety about next possible symptoms and flares, depression, feeling sad, resignation, hope (from Austria); anxiety, emotional vulnerability, depressive mood, unhappiness (from Romania); emotional influence, downcast, depressed (from Sweden); feeling of depression, anxiety about losing a job, anxiety about losing one's independence (from Switzerland). In this process, the researchers (the first author together with at least one researcher from each country) went back and forth between possible higher- and lower-level concepts and checked the scheme of concepts for each country so that meanings assigned would not be lost.

In the final step of the analysis, all concepts grouped under a specific ICF domain were linked to the corresponding ICF categories within this domain according to predefined rules ${ }^{26}$ : the concept 'emotional issues', for example, was linked to a corresponding ICF category called 'b152-emotional functions'. Concepts were linked to the most specific ICF category. If concepts were more general and no specific ICF category was available, then they were linked to ICF chapters-for example, 'chapter d5-self-care' in the component 'activities and participation'. Concepts related to personal factors were linked to ICF whole component 'personal factors' (PF) because this ICF component does not include separate categories. Concepts related to the disease itself were linked to 'health condition' (HC). In addition, we counted the concepts for each country and for each ICF component partly following the approach described as 'meaning categorisation' by Kvale. ${ }^{24}$

\section{Accuracy and rigor of the qualitative analysis}

All local principal investigators ( $\mathrm{AB}, \mathrm{CM}, \mathrm{MM} / \mathrm{CB}, \mathrm{JS}$ ) had extensive experience with qualitative research before this project. Two pages of a transcript translated into English were sent round and each investigator extracted meaning units and the concepts contained in these meaning units before starting to analyse the local data. The results of this two-page exercise were discussed together to obtain a common understanding about the meaning units and depth of concepts until consensus was 
Table 1 Demographic data of the participants in each country

\begin{tabular}{lllll}
\hline Demographic data & Austria & Romania & Sweden & Switzerland \\
\hline $\mathrm{N}$ & 20 & 10 & 17 & 16 \\
Women (\%) & $14(70)$ & $10(100)$ & $15(88)$ & $14(88)$ \\
Age (years, median (range)) & $63(33-85)$ & $42(30-56)$ & $57(30-78)$ & $62(38-80)$ \\
Disease duration (years, median (range)) & $8(2-15)$ & $6(0.5-13)$ & $10(3-32)$ & $16(2.5-48)$ \\
Diffuse/limited SSc defined according to LeRoy et a/32 & $10 / 10$ & $6 / 4$ & $4 / 13$ & $5 / 11$ \\
\hline
\end{tabular}

Because of the small sample size and the focus on the qualitative analysis in this study, no comparative statistics were calculated. Disease duration refers to the period of time since the first non-Raynaud's manifestation.

SSc, systemic sclerosis.

achieved. Before a final scheme of concepts was established, the concepts grouped under a certain ICF domain were sent back to the local investigators for evaluation and feedback. According to the suggestions of the local investigators, the concepts were then refined.

\section{RESULTS}

\section{Participants}

In total, 63 people with SSc participated in 13 focus groups (four in Austria, two in Romania, four in Sweden and three in Switzerland). Characteristics of the participants of each country are presented in table 1 . The number of participants in each focus group ranged from three to eight.

\section{Concepts obtained in the qualitative analyses}

The local investigators extracted 181 concepts in Austria, 99 in Romania, 159 in Sweden and 114 in Switzerland. Most concepts from a certain country showed similarities to the concepts derived from the qualitative data in the other countries-for example, the concepts 'problems with fingers in daily activities' from Austria were considered to be similar to 'functions of hands and arms and fine motor functions' from Romania, 'impaired hand function' from Sweden and 'impaired fine motor function of hands' from Switzerland.

In all countries, the participants stated that SSc influenced and affected functioning and health. The ICF component to which the largest number of concepts was linked was body functions and structures (32 $(37 \%)$ of the total number of 86 higher-level concepts). These concepts were also related to activities and participation and environmental and personal factors. A participant described this in the following way at the start of the group session:

In my point of view everything is spinning around the same phenomenon, which for me was and still is . . . a total upsidedown turn of everyday life. And this is mostly because of the psychological manifestations (body function), not only because of physical problems (body function). What bothers me most? Of course the symptoms of the Raynaud's syndrome bother me, the fact that my hands become blue (body function), the fact that I don't look at them when I go out (activities and participation) in cold weather (environmental factor), the fact that I look at the hands of all people. But mostly the psychological issues (body functions) bother me.

Some participants considered physical symptoms to be related to psychological functions (body functions), to activities and participation (eg, to go out), as well as to environmental factors (eg, climate). A participant expressed this relationship in the following way:

If it's 20 degrees below zero outside, you don't go out at all . . . then I was really depressed, because it was so cold for such a long time. I didn't go out to get my mail from the mail box for almost three weeks.

\section{Comparison of concepts from all countries}

Table 2 shows the scheme of higher-level concepts derived from the qualitative data analyses of all countries. Nineteen concepts (22\% of all 86 concepts) were identified in all four countries (marked in grey in the table 2). Of these, nine were body functions and structures, three activities and participation and two personal factors. Within the environmental factors, five concepts ('drugs and side effects of these', 'climate, cold weather, too much heat, cold in one's flat', 'support of partner, family, relatives, friends', 'experiences with healthcare institutions including negative experiences' and 'non-pharmacological treatment. . . healthcare institutions, social security system, benefits' (table 2)) were found in all four countries, whereas most other concepts were identified in one or two countries only. In the area of body functions and structures, activities and participation and personal factors, most concepts were found in at least two or three countries.

In total, 23 concepts ( $27 \%$ of all 86 concepts) emerged in one country only. Of these, 10 were considered to be body functions and structures by the researchers, three activities and participation and 10 environmental factors. An example is the concept 'affected sex life' which was mentioned in one country, but not in any of the other countries. A participant described 'affected sex life' in the following way:

I can talk about it - perhaps it is a stupid subject to raise-perhaps it is not, but my sex life with the cytotoxic drugs ... I don't know if everyone reacts to cytostatics in such a way . . . but I have lost the urge for things like that...

Later in the same focus group another participant expressed:

My partner dislikes that I'm tired and don't want to have sex, he thinks there's something wrong with him.

Some participants expressed the feeling that environmental factors could be both facilitators and barriers. While experiences with healthcare institutions were found to be supportive by some people with SSc (table 2), others had had negative experiences with healthcare institutions: 'took a long time until diagnosis', 'wrong treatment of uninformed professionals', 'difficulty to get an appointment' and 'no one knows what to do against dryness of mucosa'. Also in the area of body functions and personal factors, positive and negative aspects could be part of one concept. An example was the concept 'emotional issues' which included 'depression', 'anxiety', 'resignation', but also 'hope'.

\section{DISCUSSION}

This study described concepts important to people with SSc obtained in a qualitative focus-group study in four European countries. As far as we know, this is the first multicentre study on the experiences of people with SSc with a qualitative approach. Problems with swallowing/gastrointestinal symptoms, pain, fatigue and emotional distress as well as problems with household activities and impaired work have been described by 
Table 2 Concepts mainly related to the ICF components

\begin{tabular}{|c|c|c|c|c|c|}
\hline Concepts & ICF & A & $\mathbf{R}$ & $\mathbf{S}$ & $\mathrm{CH}$ \\
\hline \multicolumn{6}{|l|}{ Body functions and structures } \\
\hline Self-confidence & b1266 & & • & & \\
\hline Fatigue, lack of power and motivation, needs rest, slower pace & b130, b4552 & • & • & • & • \\
\hline Memory functions & b144 & • & & & \\
\hline Emotional issues & b152 & - & - & - & - \\
\hline Impaired speech ability & b310 & - & & • & \\
\hline Functions of the immune system & b430 & • & & • & \\
\hline Structure and functions of the skin, ulcers & b8, s810 & - & - & • & \\
\hline $\begin{array}{l}\text { Impaired tough function, numbness, sensations related to the skin, increased sensibility, loss of sensory } \\
\text { functions }\end{array}$ & b265, b840 & • & • & $\bullet$ & \\
\hline Dry mucous membranes, dry mouth, eyes, nose & b898, s898 & - & - & - & - \\
\hline Ingestion functions, swallowing problems, dysphagia, mouth too small, problems with oesophagus & b510, s510, s520 & - & - & - & - \\
\hline Digestive functions, stomach complaints, diarrhoea, bowel problems & b5, b515, s5 & - & • & • & \\
\hline Swelling of body parts & b545 & & • & • & - \\
\hline Chills & b550 & & - & & \\
\hline Function and structure of hair & b850, s840 & - & - & & \\
\hline Function and structure of nails & b860, s830 & & • & & \\
\hline Heart & b410, s4100 & - & & • & \\
\hline Kidneys & b610, b545, s6100 & - & & • & \\
\hline Pancreas & b598, s550 & • & & & \\
\hline Gall bladder & b598, s570 & & & • & \\
\hline Lung, bronchiae & b440, s4301, s43010 & - & • & • & - \\
\hline Stiffness (of muscles, joints, fingers, knees, skin, tendons), cramps, calcification & b710, b715, b8, s810, s770 & • & - & • & - \\
\hline Fine motor skills of the hand, turning, twisting and fumbling & $d 440, d 4453$ & & - & • & - \\
\hline Use of arm and hand & $\mathrm{d} 445$ & & • & - & • \\
\hline Using public transportation & d470 & & • & • & \\
\hline Driving a car & d4751 & • & & • & \\
\hline Eating and drinking, eating dry food & $\mathrm{d} 550, \mathrm{~d} 560$ & & - & • & • \\
\hline Self-care & d5 & & & • & - \\
\hline $\begin{array}{l}\text { Applying self-treatment strategies, such as movement, exercise, other strategies to keep hands warm, } \\
\text { higher temperature at home, being occupied, drinking during eating helps, stopping to smoke, going to a spa, } \\
\text { special shampoo against hair loss, diet }\end{array}$ & $\mathrm{d} 570$ & • & & • & \\
\hline Preparing meals & $\mathrm{d} 630$ & & - & • & • \\
\hline Household activities & d640 & • & • & • & • \\
\hline Maintaining dwelling & d6501 & & & • & \\
\hline Gardening & d6505 & & & • & \\
\hline Caring for children/grandchildren & $\mathrm{d} 660$ & & & • & \\
\hline Paid work and productive activities & d8 & - & • & • & - \\
\hline Riding a bicycle & d4750 & & & • & • \\
\hline Shopping, entering into cold rooms in supermarkets & d6200 & & - & • & - \\
\hline $\begin{array}{l}\text { Leisure activities such as sports, skiing, dancing, playing an instrument, listening to music, doing crafts, } \\
\text { fishing, doing creative things, singing in a choir, gardening }\end{array}$ & d920 & & • & • & • \\
\hline Socialising, loneliness & d9205 & • & & • & • \\
\hline \multicolumn{6}{|l|}{ Environmental (e) and personal factors (PF) in the ICF as well as to the health condition (HC) itself } \\
\hline Drugs and side effects of these & e1101 & • & • & • & - \\
\hline Means for keeping warm such as warming pads, gloves, mittens & e1150 & • & & - & \\
\hline Hard to find the right clothes that keep warm & e1150 & • & & • & \\
\hline Assistive devices, adaptations, adapted car, electronic devices & e115 & • & & • & • \\
\hline
\end{tabular}


Table 2 Continued

\begin{tabular}{|c|c|c|c|c|c|}
\hline Concepts & ICF & A & $\mathbf{R}$ & $\mathbf{S}$ & CH \\
\hline Crowds & $\mathrm{e} 215$ & & $\bullet$ & & \\
\hline Climate, cold weather, too much heat, cold in one's flat & e225, e298 & • & • & $\bullet$ & $\bullet$ \\
\hline Noise & e250 & & • & & \\
\hline Support of partner, family, relatives, friends & e310, e315 & $\bullet$ & $\bullet$ & $\bullet$ & $\bullet$ \\
\hline Support of other people with diseases & e325 & & $\bullet$ & $\bullet$ & \\
\hline Support of colleagues & e325 & & & $\bullet$ & \\
\hline Support of employers & e330 & & & $\bullet$ & \\
\hline Support of personal assistant & e340 & & & & $\bullet$ \\
\hline Support of strangers & e345 & $\bullet$ & & & \\
\hline Support of pets & e350 & $\bullet$ & & $\bullet$ & \\
\hline Support of health professionals specialised for SSc & e355 & & • & $\bullet$ & \\
\hline Attitudes of family members & e410 & & $\bullet$ & $\bullet$ & \\
\hline Attitudes of strangers & e445 & & $\bullet$ & & \\
\hline Attitudes of friends & e420 & • & & & \\
\hline Attitudes of colleagues & e425 & & $\bullet$ & $\bullet$ & \\
\hline Attitudes of employers & e430 & & & • & \\
\hline $\begin{array}{l}\text { Attitudes of health professionals, such as a lack of understanding, needing to go to a private practice } \\
\text { and pay for the service }\end{array}$ & e450 & • & & • & \\
\hline Employers' policies & $\mathrm{e}$ & & • & & \\
\hline Experiences with healthcare institutions, including negative experiences & e450 & $\bullet$ & $\bullet$ & $\bullet$ & $\bullet$ \\
\hline $\begin{array}{l}\text { Non-pharmacological treatment, wax bath, treatment of dentists, treatment of occupational } \\
\text { therapists, treatment of physiotherapists, (treatment in) healthcare institutions, social security } \\
\text { system, benefits }\end{array}$ & e5 & • & • & • & • \\
\hline $\begin{array}{l}\text { Positive experience of the disease, being in control, being strong owing to having mastered the } \\
\text { disease, positive attitude towards disease }\end{array}$ & PF & • & • & • & • \\
\hline $\begin{array}{l}\text { Struggle to master one's life with the disease, such as unclear future, unclear outcome, needing to } \\
\text { compromise, change of expectations }\end{array}$ & PF & • & • & • & • \\
\hline Changing the way of doing things, adapting daily activities to own abilities & $\mathrm{PF}$ & - & & - & $\bullet$ \\
\hline Mental and physical exhaustion, impaired fitness as referring to the current individual state of the body & $\mathrm{PF}$ & & $\bullet$ & $\bullet$ & \\
\hline $\begin{array}{l}\text { Own attitudes towards SSc, towards being ill, towards accepting help, towards drugs, feeling guilt towards } \\
\text { partners, family members and children, not viewing oneself as ill, focusing on what one can do }\end{array}$ & PF & & • & • & • \\
\hline Gender-specific differences: losing hair is terrible for a woman, change of gender roles in relationships & $\mathrm{PF}$ & $\bullet$ & • & & \\
\hline Course of the disease & $\mathrm{HC}$ & • & $\bullet$ & $\bullet$ & \\
\hline
\end{tabular}

Higher level concepts which relate to ICF categories are described in the tables ordered by ICF component. Lower-level concepts are not shown in the tables. Concepts that emerged in all four countries are marked in bold. 'A' refers to Austria, ' $R$ ' to Romania, 'S' to Sweden and 'CH' to Switzerland. ' $b$ ' categories are included in the ICF component body functions, ' $s$ ' are body structures, 'd' activities and participation and ' $e$ ' environmental factors.

A, Austria; CH, Switzerland; R, Romania; S, Sweden.

ICF, International Classification of Functioning, Disability and Health; SSc, systemic sclerosis.

patients with SSc in earlier studies, ${ }^{9} 14$ consequences also found in all four countries involved in our study. Personal factors like struggle to master one's life were expressed in different ways in the countries in our study. Mendelson and Poole, ${ }^{15}$ for example, also found that taking control of one's illness was a necessary component to maintain a high quality of life.

Most concepts were considered by the researchers to be body functions and structures followed by environmental factors. Importantly, similar concepts were derived in different countries; fewer than one-third were found in one country only. The categories found in one country only with the highest percentage (more than one-third of these) were linked to the ICF component environmental factors. This may relate to different healthcare and social security systems, different policies for accessibility to services, but also issues such as public transportation. Nevertheless, people with SSc in Europe may experience rather similar problems and may have similar values-even though countries from east, north and central Europe were involved in this study-while contextual factors may be more different when compared with other continents. We expected to find differences in the environmental factors due to the different situations people are facing; for example, Austria is a conservative corporatist welfare state ${ }^{27}$ with the traditional values of a patriarchal society, compared with, for example, a Scandinavian welfare regime in Sweden with higher rates of part-time employment among women. ${ }^{28}$ However, we did not expect to find such considerable differences in the area of body functions and structures. This may be due to cultural values that affect the topics mentioned in a focus group as, for example, affected sex life was only mentioned in Sweden, but not in any other country.

While negative and positive aspects were described by the participants in body functions and structures and environmental and personal factors, the concepts in the area of activities and participation related only to negative aspects and dysfunction. In a focus-group study of hand osteoarthritis, just one positive aspect in the area of activities and participation was described, which was the involvement in sports experienced as helpful by the participants, ${ }^{23}$ while in a similar study in people with systemic lupus erythematosus also only negative issues were identified in the area of activities and participation. ${ }^{22}$ In the systemic lupus erythematosus study which was conducted only in Austria, a similar number of concepts were identified (92 in total, 28 of these related to body functions and structures, 24 to activities and participation, 25 to environmental factors, 2 to the health condition itself, 6 to personal factors and 7 could not be linked to the ICF). This may also be a specific factor of the ICF because positive experiences such as being strong owing to having mastered the disease were linked to personal factors rather than activities and participation according to rules for 'translating' concepts into ICF 'language'. Therefore, it may be important to include resources and facilitators, in addition to the usual problems and barriers, in patient-reported outcome measures 
and instruments. From this perspective, multidimensional scales may be desirable. The concepts of our study may also be used to analyse the validity of patient-reported instruments, but also for the development of new instruments or the development of an ICF core set for SSc, which is a list of typical ICF categories affected in a certain condition. ${ }^{29}$

A limitation of our study was that only people with SSc from Europe participated. We therefore recommend that further studies with a similar design are carried out in other parts of the world-for example, places with a different climate. Furthermore, different organ involvement of patients might have influenced which ICF categories were identified in the area of body functions and structures. However, in the area of activities and participation and personal factors, the participants of this study identified similar issues consistently in at least two or three different countries. A limitation of group interviews may be that they do not allow for in-depth descriptions from individual participants and thus may limit the richness of the data. This may also be related to the presence of two researchers (one moderator and one assistant) during the group discussion.

Most participants in this study were women, which we expected because the prevalence of SSc has an overall female:male ratio of about 3:1.30 31 Gender-specific differences were explicitly raised in the focus groups in Austria and Romania, but interestingly, were not mentioned in the other two countries. An example was the following description from a participant: "We are also women and each of us cares, more or less, about our looks. Then it is a major inconvenience that we are no longer in control of our hands." However, concerns about changing the appearance of one's body may be also related to the concept 'body image and appearance, including weight maintenance/loss', which emerged in Austria, Romania and Sweden, but not in Switzerland. Furthermore, women from the countries in which no gender-specific differences were raised might have considered that appearance is not gender-specific. Concerns with physical appearance have also been reported in other qualitative studies, ${ }^{14}$ ${ }^{16}$ suggesting that it might be a risk of stigmatisation. ${ }^{16}$

\section{CONCLUSION}

Twenty-two per cent of all concepts were identified in all four countries. In routine clinical care, these concepts could be used to guide assessment of patients with SSc from a comprehensive bio-psycho-social perspective. In rheumatological rehabilitation and interdisciplinary team care, these aspects could be seen as core aspects and consequences of the disease to be addressed in every patient.

Acknowledgements The authors thank all patients who participated in this study, Bozena Möller, MD and Ines Nilsson, OT from Sunderby Hospital, Luleå, Sweden, and Martina Sadlonova, OT from Vienna, Austria.

Funding This study was partly funded by a grant from the Standing Committee of Health Professionals in Rheumatology in EULAR, and the County Council of Norrbotten, Sweden.

Patient consent Obtained.

Ethics approval This study was conducted with the approval of the institutional review boards and ethics committees of Vienna (Medical University, Austria), Bucharest (Romania), Luleå (Sweden), Zurich (Switzerland).

Provenance and peer review Not commissioned; externally peer reviewed.

\section{REFERENCES}

1. White B. Immunopathogenesis of systemic sclerosis. Rheum Dis Clin North Am 1996;22:695-708.
2. Clements PJ, Hurwitz EL, Wong WK, et al. Skin thickness score as a predictor and correlate of outcome in systemic sclerosis: high-dose versus low-dose penicillamine trial. Arthritis Rheum 2000:43:2445-54.

3. Clements PJ, Lachenbruch PA, Ng SC, et al. Skin score. A semiquantitative measure of cutaneous involvement that improves prediction of prognosis in systemic sclerosis. Arthritis Rheum 1990;33:1256-63.

4. Poole JL, Steen VD. The use of the Health Assessment Questionnaire (HAO) to determine physical disability in systemic sclerosis. Arthritis Care Res 1991;4:27-31.

5. Poole JL, Watzlaf VJ, D'amico F. A five-year followup of hand function and activities of daily living in systemic sclerosis (scleroderma). J Hand Ther 2004;17:407-11.

6. Poole JL, Gallegos M, O'Linc S. Reliability and validity of the Arthritis Hand Function Test in adults with systemic sclerosis (scleroderma). Arthritis Care Res 2000;13:69-73

7. Ruof J, Brühlmann P, Michel BA, et al. Development and validation of a selfadministered systemic sclerosis questionnaire (SySQ). Rheumatology (Oxford) 1999;38:535-42.

8. Casale R, Buonocore M, Matucci-Cerinic M. Systemic sclerosis (scleroderma): an integrated challenge in rehabilitation. Arch Phys Med Rehabil 1997;78:767-73.

9. Sandqvist G, Akesson A, Eklund M. Daily occupations and well-being in women with limited cutaneous systemic sclerosis. Am J Occup Ther 2005;59:390-7.

10. Hudson M, Thombs BD, Steele R, et al.; Canadian Scleroderma Research Group. Health-related quality of life in systemic sclerosis: a systematic review. Arthritis Rheum 2009;61:1112-20.

11. World Health Organization. ICF - International Classification of Functioning, Disability and Health. Geneva: WHO, 2001.

12. Carr A, Hewlett $S$, Hughes $R$, et al. Rheumatology outcomes: the patient's perspective. J Rheumatol 2003;30:880-3.

13. Hewlett SA. Patients and clinicians have different perspectives on outcomes in arthritis. J Rheumatol 2003;30:877-9.

14. Suarez-Almazor ME, Kallen MA, Roundtree AK, et al. Disease and symptom burden in systemic sclerosis: a patient perspective. J Rheumatol 2007;34:1718-26.

15. Mendelson C, Poole JL. Become your own advocate: advice from women living with scleroderma. Disabil Rehabil 2007;29:1492-501.

16. Joachim G, Acorn S. Life with a rare chronic disease: the scleroderma experience. J Adv Nurs 2003:42:598-606.

17. Clarke A. Focus group interviews in health-care research. Prof Nurse 1999;14:395-7.

18. Parsons M, Greenwood J. A guide to the use of focus groups in health care research: part 1. Contemp Nurse 2000;9:169-80.

19. Preliminary criteria for the classification of systemic sclerosis (scleroderma). Subcommittee for scleroderma criteria of the American Rheumatism Association Diagnostic and Therapeutic Criteria Committee. Arthritis Rheum 1980;23:581-90.

20. Jones K. The Turn to a Narrative Knowing of Persons: One Method Explored. Nursing Times Research, 2002:1-11. http://www.angelfire.com/zine/kipworld/ The turn.pdf (accessed 1 Dec 2010).

21. Stamm TA, Nell V, Mathis M, et al. Concepts important to patients with psoriatic arthritis are not adequately covered by standard measures of functioning. Arthritis Rheum 2007;57:487-94.

22. Stamm TA, Bauernfeind B, Coenen M, et al. Concepts important to persons with systemic lupus erythematosus and their coverage by standard measures of disease activity and health status. Arthritis Rheum 2007;57:1287-95.

23. Stamm T, van der Giesen F, Thorstensson C, et al. Patient perspective of hand osteoarthritis in relation to concepts covered by instruments measuring functioning a qualitative European multicentre study. Ann Rheum Dis 2009;68:1453-60.

24. Kvale S. Interviews - An Introduction to Qualitative Research Interviewing. CA: Thousand Oaks, Sage 1996.

25. Karlsson G. Psychological Qualitative Research from a Phenomenological Perspective. Stockholm: Almquist \& Wiskell International 1995

26. Cieza A, Geyh S, Chatterji S, et al. ICF linking rules: an update based on lessons learned. J Rehabil Med 2005;37:212-18.

27. den Dulk L, van Doorne-Huiskes A. Social policy in Europe: its impact on families and work. In: Crompton R, Lewis S, Lyonette C, eds. Women, Men, Work and Family in Europe. New York, NY: Palgrave Macmillan 2007:35-57.

28. Bambra C, Eikemo TA. Welfare state regimes, unemployment and health: a comparative study of the relationship between unemployment and self-reported health in 23 European countries. J Epidemiol Community Health 2009;63:92-8.

29. Cieza A, Ewert T, Ustün TB, et al. Development of ICF Core Sets for patients with chronic conditions. J Rehabil Med 2004;44(Suppl):9-11.

30. Mendoza F, Derk CT. Systemic sclerosis mortality in the United States: 1999-2002 implications for patient care. J Clin Rheumatol 2007:13:187-92.

31. Bond C, Pile KD, McNeil JD, et al. South Australian Scleroderma Register: analysis of deceased patients. Pathology 1998;30:386-90.

32. LeRoy EC, Black C, Fleischmajer R, et al. Scleroderma (systemic sclerosis): classification, subsets and pathogenesis. J Rheumatol 1988;15:202-5. 